\title{
ワックス針入度のレオロジー的意義について
}

\author{
上原陵 一*・堀井武夫*・畑 忠 男*
}

\section{A Rheological Consideration of Needle Penetration of Waxes.}

\author{
Ryoichi Uehara, Takeo Horii and Tadao Hata
}

\begin{abstract}
Depth of penetration have been measured continuously from time to time by the use of a penetrometer of the type JIS K 2530 with some modification. Velocity of penetration was determined by graphycally differentiating the curve correlating the depth with time. Shearing stress at the osculating plane of the apex of needle of the penetrometer reduces with increase of the depth. As the results, relation of the velocity and the shearing stress can be correlated in a figure. By extrapolating the correlating curve to the point at which the velocity is zero, yield value of waxes can be easily determind. It was found that needle penetration number usually used as an index of hardness pf waxes inversely proportional to the 0.6 power of the yield value. Consequently, the [needle penetration number can be employed as an quantitative index of the hardness of waxes.
\end{abstract}

\section{1 まえがき}

種々のワックスが化粧品用原料として用いちられてい るが，その物性および試験法についてはあまり深い注意 が払われていない。これはワックスが補助材料として用 いられることが多いことに由来するものであろうが，他 の分野でも大体同じような事情にある。「化粧品用原料 標準規格」には，種々のワックスが採り上げられている が, その試験法としては化学試験のみが記載されており, 物理的特性については全く触れていない。一方ワックス は主としてその物理的特性を利用して使われており（化 学的特性を無視してよいと言うことでは無いが), その 中でも「硬さ」は重要な性質である。

我が国に括いては，ワックスの「硬さ」は針入度によ って比較されることが多い。しかしこれ以外にもワック スの「硬さ」を測る方法が無いわけではなく，参考まで に Table-1 に各国で行なわれている例を括めた。

Table-1. Methods of tasting hardness of waxes

\begin{tabular}{c|c|c|c}
\hline Warth & DGF $^{2)}$ & ASTM $^{3)}$ & JIS $^{4)}$ \\
\hline $\begin{array}{l}\text { Durometer } \\
\text { haydness }\end{array}$ & $\begin{array}{c}\text { Harte } \\
\text { (Brinell- } \\
\text { methode) }\end{array}$ & & \\
\hline $\begin{array}{l}\text { Penetration } \\
\text { test }^{6)}\end{array}$ & Konsistenz & $\begin{array}{l}\text { Penetration } \\
\text { test }\end{array}$ & $\begin{array}{l}\text { Penetration } \\
\text { test }\end{array}$ \\
\hline $\begin{array}{l}\text { Consistency } \\
\text { test }^{7}\end{array}$ & & & \\
\hline
\end{tabular}

* 日興理化学産業株式会社（東京都千代田区神田須田町 126)

* Nikko Scientific and Chemical Industry Co.,Ltd.
針入度は言うまでも無く, 一定の形状の先の尖った針 を一定の荷重で試料の中へ押し込み，一定時間（通常 5 秒）後に荷重を取り除いて, 針が試料の表面から沈んだ 深さを測ったもの（通常 $1 / 10 \mathrm{~mm}$ 単位で表わされる） である。このやり方は他の硬度計でも同様であるが，わ れわれが日常生活で物の硬さを較べる場合，その表面を 指で押したり，爪を立ててみたりした感じで判断してい ることを機械的にモデル化したものと考えて良いである う。このため, 従来針入度は単なる経験的数值として用 いられているにすぎず，定量的な意義についてはあまり 深く考えられていなかった。

われわれは，日常生活において「硬さ」という言葉它 しばしば使っているが，この内容は必ずしも判然として いないことが多い。大ざっぱに言って「硬さ」とは「変 形に対する抵抗」を意味するものであろうが，変形のし 方には弾性変形, 塑性变形等いろいろある。古くから 「硬さ」の試験が行なわれてきた金属材料については, 針入度計と似たような原理で種々の硬度計が開発されて きているが，種々の硬度計で測った「硬度数」の間に は, 定量的な関係があり, またビッカース硬度数 $H_{V}$ と 降伏応力 $\tau_{y}$ の間には $H_{V}=3 \tau_{\boldsymbol{y}}$ なる関係が成立するこ とが知られており10)，金属においては「硬度数」は塑性 変形の起こり易さ」を定量的に表示しているものと考え られている。

われわれは従来の針入度計に小改造を加え, 針入度一 時間の関係を連続的に測定し，これにより試料の降伏応 力を求め得ることを見出した。さらにこれ等と従来測定 されてきた針入度ととの関係を検討することにより，両 
者の間に定量的な関係が存在することが明らかとなり， 針入度を硬さの定量的基準として用い得ることが結論さ れた。以下，化粧品用原料として用いられることの多い ワックスについて，これを説明する。

\section{2 針入度に関する Pendelton 等の考え方 ${ }^{11,12)}$}

Pendelton は，針先の形を無視するか，または適当な 補正を数式上で加えることによって，Fig.-1 に原理を示 したような共軸円筒形粘度計 (pochettino 粘度計) と見做 すことができると考え，これにより針入度計を粘度と関 連づけられると考えた。
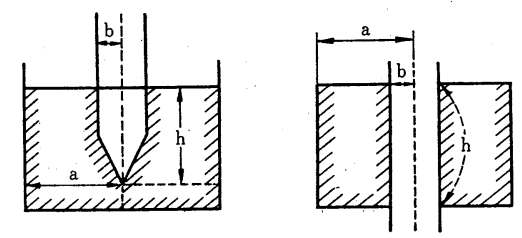

Fig.-1 Analogy of needle penetrotion to pochettino viscometer

針入度の測定において，針が試料の中へ入った場合を Fig.-1 のように, 針定粘度計の内筒, 試料の入ったカッ プを外筒と考え, 針の入った深さ! $h(\mathrm{~cm})$, 内筒の落下速 度 $d h / d t(\mathrm{~cm} / \mathrm{sec})$, 試料の粘度 $\eta$ (poise), 内筒と外筒 の半径をそれぞれ $b, a(\mathrm{~mm})$, 内筒に作用する外力定, $f$ (dgne), 時間を $t(\mathrm{sec})$ とすると，(1)式が得られる。

$$
\frac{d h}{d t}=\frac{f}{2 \pi h \eta} \ln \frac{a}{b}
$$

$t=0$ 亿扔いては, $p=0$ であるから，針の形を無視し て(1)式を $t=0$ より $t=t$ までの間で積分すると(2) 式が得られる。

$$
h^{2}=\frac{f t}{\pi \eta} \ln \frac{a}{b}
$$

荷重を $W g$ とすると， $f=980 \mathrm{~W}$ また針入度測定に常 用されている条件, $W=100 \mathrm{~g}, t=5 \mathrm{sec}, a=2.75 \mathrm{~cm}, b$ $=0.05 \mathrm{~cm}, 1 / 10 \mathrm{~mm}$ 単位で表わした針入度 $P$ 党用いる と, (3)式が得られる。

$$
\eta=\frac{6.25 \times 10^{9}}{P^{2}} \text { [poise] }
$$

Pendelton は (3) 式により針入度から粘度を求めるこ とができると考光たわけであるが，われわれが針入度か ら感じている「硬さ」を粘度で置き換えて考光る考へ方 に注疑問がある。また針入度計を Pochettino 粘度計と 相似させることは，針入度が針の先端の円錐部分に比べ て充分に大きい軟かい物質の場合にはあまり無理がない ように思われるが，ワックスのように針入度が比較的小 さい材料の場合には不適当である。

\section{3 針入度 - 時間曲線より 降伏応力を求める方法}

普通，針入度の測定は時間 5 秒で行なわれているが， これを連続的に測定すれば針入度と時間の関係を Fig.-2 の左のように求めることができる。針入度 - 時間曲線を 図上で微分すれば，各時間に敊ける $d h / d t$ 深 Fig.-2 の 右のように求めることができる。
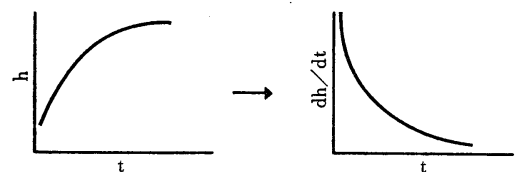

Fig.-2 An illustration of the method of determing uelocity of penetration.

針の先端は Fig.-3 のような形をしており, 試料と針 先が接触する面積は針入度の函数として式 (4)のように 変化する。

$$
A=\pi r l=\left(\pi \beta \sqrt{1+\beta^{2}}\right) h^{2} \ldots
$$

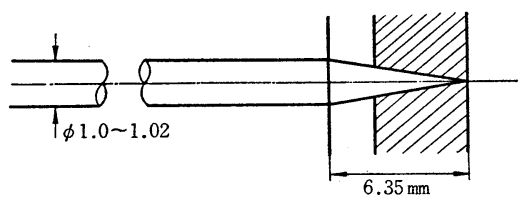

Fig.-3 The schape ot the apex of the needle

$A$ は針入部の面積, $\beta$ 注針先の円錐部の半径と高さの 比を示す。連続測定の場合のダイヤルゲージの荷重の変 化をも考光に入れると，針入度に対応する針入部分の 「ずり」応力の大さは(5)式で表わされる。

$$
\tau=\frac{W}{A}=\frac{W_{0}-\alpha h}{\left(\pi \beta \sqrt{1+\beta^{2}}\right) h^{2}} .
$$

したがって Fig.-2 のようにして求めた針入速度 $d h / d t$

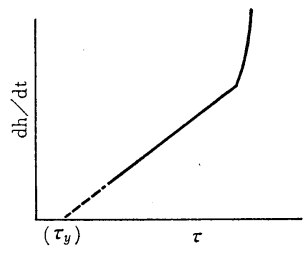

Fig.-4 The principle of evaluating yield volue と応力 $\tau$ の関係は，Fig.-4 のように表わされる。Fig.4 において速度 - 応力曲線 を $d h / d t=0$ の所まで外捜 して得られる $\tau_{y}$ は, 試料 の降伏応力を示すことは容 易に理解される。このよう にして，針入度の測定から 降伏応力を求めることができる。

\section{4 実 験 方 法}

\section{1 装置}

JIS K-2530 に規定されている針入度計を用いた。た 


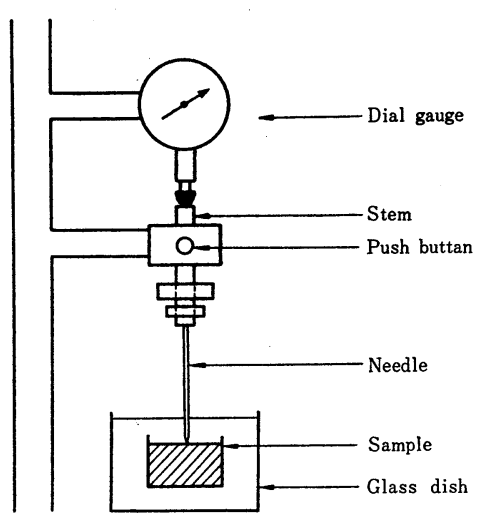

Fig.-5 Penetrometer

だし目盛板を取り除き，その代りに連続的測定が可能の ように, Fig.-5 に示したようにダイヤルゲージ（JIS， B-7503）を取り付けた。その他の付属装置はすべて K2530 の規定どおりとした。装置の大要を Fig.-5 に示し た。

\section{2 測定用試料の準備}

試料をなるべく低温で部分的に過熱しないようにして 溶融するる。溶融試料をよくかきまぜ均質にし気泡を除い てから, 試料容器 (内径 $55 \mathrm{~mm}$, 深さ $35 \mathrm{~mm}$ ) に流し込 み，その深さを試料が試験温度に冷えたとき針の針入す る距離より $10 \mathrm{~mm}$ 以上深くする。次いで試料容器を $24^{\circ}$ 以上の所飞 1.5 乃至 2 時間放置し, これをガラス皿 (内径 $110 \mathrm{~mm}$, 深さ $60 \sim 75 \mathrm{~mm}$ ) と並べて, 試験温度 $\left(25^{\circ} \mathrm{C}\right)$ の $\pm 0.1^{\circ} \mathrm{C}$ に保った水浴中で 1 乃至 1.5 時間 放置した。

\section{3 測定操作}

ガラス皿に試料容器を移し, 水浴中の水を満たしたま まこれを針入度計の試料台上に載せる。針入度計の鍾お よび針を取り付けた黄銅管上端にダイヤルゲージを取り 付け，ダイヤルゲージのスピンドルを押し上げ，０の位 置に黄銅管を固定する。試料台を調節して針の先端を試 料の表面に接触させる。次いで黄銅管停止ボタンを押し 針を針入させると同時に，針入開始より 5 秒ごとに， 針入深さをダイヤるゲージで読みとる。

\section{4 降伏応力の求め方}

1) $d h / d t:$ 測定した $t$ 秒ごとの針入距離 $h$ から $h-$ $t$ 線図を作成し，図上微分により各時間における $d h / d t$ を求める。

2) ずり応力 $\tau:$ 時間 $t$ における荷重を $W \mathrm{~g}, t=0$ において $W=W_{0}$ とすると， $W=W_{0}-\alpha h$ なる関倸が成 立する。 $\alpha$ はダイヤルゲージに固有の比例定数であって
今回用ひたダイヤルゲージでは $\alpha=14 \mathrm{~g} / \mathrm{mm}$ ，また $W_{0}$ $=170 \mathrm{~g}$ であった。したがって時間 $t$ にお㤝る荷重の大 きさは(6)式で表わされる。

$$
W=170-14 h
$$

また JIS K-2530 に規定されている針においては， $\beta=$ 0.07874 であり，(5)および $(6)$ 式とあわせて時間 $t$ 亿 おける「ずり」応力は $(7)$ 式で表わされる。

$$
\tau=\frac{170-14 h}{0.2479 h^{2}} \text {. }
$$

3) 降伏応力 $\left.\tau_{y}: 1\right)$ により求めた $d h / d t z(7)$ 式よ り得られた $\tau$ の値より, $d h / d t-\tau$ 関係図を作り, 直線 部分を $d h / d t=0$ まで外搜して $\tau_{y}$ が求められる。

\section{5 実 験 結 果}

実験に用いたワックスの性状は Table-2 に示した。

Table-2 Nature of Waxes

\begin{tabular}{l|c|c|c|c|c|c}
\hline \multicolumn{1}{c|}{ Waxes } & AV. & SV. & IV. & $\begin{array}{c}\text { SP(s) } \\
{\left[{ }^{\circ} \mathrm{C}\right]}\end{array}$ & $\begin{array}{c}\mathrm{MP} . \\
{\left[{ }^{\circ} \mathrm{C}\right]}\end{array}$ & NP. \\
\hline Candelilla wax & 15.9 & 42.3 & & & 70.2 & 3 \\
Montan wax & 15.8 & & & & 79.7 & 8 \\
Paraffin $\left(165^{\circ} \mathrm{F}\right)$ & 0 & 0 & & & 72.0 & 12 \\
Paraffin $\left(125^{\circ} \mathrm{F}\right)$ & & & & 58.4 & 53.4 & 21 \\
Bees wax & 18.2 & 91.5 & 7.5 & & 62.6 & 25 \\
Hydrogenated & 0.99 & 130.1 & 0.8 & & 51.3 & 26 \\
spermaceti & & & & 73.4 & 78.1 & 31 \\
Microcrystalline & & & & & & \\
wax & & & & \\
\hline
\end{tabular}

測定の結果は Table-3，-4，-5 に示した。 $25^{\circ} \mathrm{C}$ にお いては，実験に用いた 7 種のワックスのすべてについて 測定結果を示したが， $35^{\circ} \mathrm{C}$ においてはキャンデリラワ ッヤスとモンタンワックスについてのタとの結果を示し た。これ以外のワックス，すなわちパラフィンワックス $125^{\circ} \mathrm{F}$ および $165^{\circ} \mathrm{F}$, 蜜ロウ, 硬化鯨ロウ，マイクロク リスタリンワックスについては， $35^{\circ} \mathrm{C}$ では信頼するに 足りる值が得られなかった。これ等の材料は $35^{\circ} \mathrm{C} て ゙ は$ 軟かすぎて本報に示す方法によって解析を行なうために は，針入度が大きくなりすぎるためと考光られる。

$d h / d t$ と $\tau$ との関係は, キャンデリラワックスとモ ンタンワックスについて Fig.-6, パラフィンワックス, 蜜ロウ, 硬化鯨ロウ, マイクロクリスタリンワックスに ついては Fig.-7 に示した。

\section{6 降伏応力の決定と針入度との関係}

実駼結果に基づいて， 7 種のワックスの $d h / d t-\tau$ 線図 より求めた降伏応力の值は Table-6 亿示した。針入度が 大きくなるほど降伏応力が小さいととが明らかに示され ている。また $25^{\circ} \mathrm{C}$ における $\tau_{\boldsymbol{y}}$ と通常の方法で測った針 
Table-3 Results of Experiments

\begin{tabular}{c|c|c|c|c|c|c|c|c|c}
\hline Waxes & \multicolumn{2}{|c|}{ Candelilla wax } & \multicolumn{2}{c|}{ Montan wax } & \multicolumn{3}{c}{ Paraffin $\left(165^{\circ} \mathrm{F}\right)$} \\
\hline Temp. & \multicolumn{2}{|c|}{$25^{\circ} \mathrm{C}$} & \multicolumn{2}{c|}{$25^{\circ} \mathrm{C}$} & \multicolumn{3}{c}{$25^{\circ} \mathrm{C}$} \\
\hline Time & $\bar{h}(\mathrm{~mm})$ & $\begin{array}{c}\tau \\
\left(\mathrm{g} / \mathrm{mm}^{2}\right)\end{array}$ & $\begin{array}{c}d h / d t \\
(\mathrm{~mm} / \mathrm{sec})\end{array}$ & $\begin{array}{c}\vec{h} \\
(\mathrm{~mm})\end{array}$ & $\begin{array}{c}\tau \\
\left(\mathrm{g} / \mathrm{mm}^{2}\right)\end{array}$ & $\begin{array}{c}d h / d t \\
(\mathrm{~mm} / \mathrm{sec})\end{array}$ & $\begin{array}{c}\bar{h} \\
(\mathrm{~mm})\end{array}$ & $\begin{array}{c}\tau \\
\left(\mathrm{g} / \mathrm{mm}^{2}\right)\end{array}$ & $\begin{array}{c}d h / d t \\
\left(\mathrm{~mm}^{2} / \mathrm{sec}\right)\end{array}$ \\
\hline 5 & 0.681 & & & 1.489 & 276 & 0.0210 & 2.088 & 133 & 0.060 \\
10 & 0.708 & 1290 & 0.0045 & 1.566 & 249 & 1.0125 & 2.235 & 115 & 0.021 \\
15 & 0.727 & 1235 & 0.0030 & 1.612 & 234 & 0.0083 & 2.312 & 106 & 0.012 \\
20 & 0.739 & 1200 & 0.0025 & 1.649 & 222 & 0.0060 & 2.355 & 102 & 0.0090 \\
25 & 0.751 & 1160 & 0.0021 & 1.678 & 214.5 & 0.0052 & 2.406 & 97.5 & 0.0070 \\
30 & 0.761 & 1128 & 0.0018 & 1.701 & 208 & 0.0044 & 2.437 & 94 & 0.0057 \\
35 & 0.768 & 1108 & 0.0015 & 1.722 & 203 & 0.0039 & 2.463 & 91.5 & 0.0047 \\
40 & 0.775 & 1088 & 0.0012 & 1.740 & 198.5 & 0.0035 & 2.484 & 90.5 & 0.0040 \\
45 & 0.782 & 1070 & 0.0010 & 1.757 & 194.5 & 0.0032 & 2.503 & 89 & 0.0034 \\
50 & 0.788 & 1052 & 0.0010 & 1.772 & 190.5 & 0.0028 & 2.518 & 88 & 0.0026 \\
55 & 0.793 & 1040 & 0.0010 & 1.785 & 187.5 & 0.0024 & 2.529 & 87 & 0.0024 \\
60 & 0.797 & 1028 & 0.0009 & 1.796 & 185 & 0.0021 & 2.542 & 86 & 0.0022 \\
\hline
\end{tabular}

Table-4 Resulta of Experiments

\begin{tabular}{|c|c|c|c|c|c|c|c|c|c|}
\hline Waxes & \multicolumn{3}{|c|}{ Paraffin $\left(125^{\circ} \mathrm{F}\right)$} & \multicolumn{3}{|c|}{ Rees wax } & \multicolumn{3}{|c|}{$\begin{array}{l}\text { Hydrogenated } \\
\text { spermacet }\end{array}$} \\
\hline Temp & \multicolumn{3}{|c|}{$25^{\circ} \mathrm{C}$} & \multicolumn{3}{|c|}{$25^{\circ} \mathrm{C}$} & \multicolumn{3}{|c|}{$25^{\circ} \mathrm{C}$} \\
\hline $\begin{array}{l}\text { Time } \\
(\mathrm{sec})\end{array}$ & $\begin{array}{c}\bar{h} \\
(\mathrm{~mm})\end{array}$ & $\begin{array}{c}\tau \\
\left(\mathrm{g} / \mathrm{mm}^{2}\right)\end{array}$ & $\begin{array}{c}d h / d t \\
(\mathrm{~mm} / \mathrm{sec})\end{array}$ & $\begin{array}{c}\bar{h} \\
(\mathrm{~mm})\end{array}$ & $\left(\stackrel{\tau}{\mathrm{g} / \mathrm{mm}^{2}}\right)$ & $\begin{array}{c}d h / d t \\
(\mathrm{~mm} / \mathrm{sec})\end{array}$ & $\begin{array}{c}\bar{h} \\
(\mathrm{~mm})\end{array}$ & $\stackrel{\tau}{\tau}\left(\mathrm{g} / \mathrm{mm}^{2}\right)$ & $\begin{array}{c}d h / d t \\
(\mathrm{~mm} / \mathrm{sec})\end{array}$ \\
\hline 5 & 2.84 & 66.5 & 0.020 & 2.51 & 88.3 & 0.055 & 3.29 & 47.3 & 0.045 \\
\hline 10 & 2.94 & 61.5 & 0.017 & 2.78 & 70.0 & 0.045 & 3.52 & 40.3 & 0.036 \\
\hline 15 & 3.01 & 58.3 & 0.014 & 2.97 & 60.1 & 0.034 & 3.65 & 36.9 & 0.019 \\
\hline 20 & 3.07 & 55.8 & 0.011 & 3.11 & 54.0 & 0.027 & 3.71 & 35.5 & 0.011 \\
\hline 25 & 3.12 & 53.6 & 0.010 & 3.23 & 49.4 & 0.020 & 3.75 & 34.6 & 0.010 \\
\hline 30 & 3.17 & 51.5 & 0.009 & 3.32 & 46.3 & 0.017 & 3.81 & 33.3 & 0.009 \\
\hline 35 & 3.21 & 50.4 & 0.008 & 3.40 & 43.8 & 0.015 & 3.84 & 32.6 & 0.008 \\
\hline 40 & 3.26 & 48.4 & 0.008 & 3.47 & 41.7 & 0.011 & 3.89 & 31.5 & 0.006 \\
\hline 45 & 3.30 & 47.0 & 0.007 & 3.52 & 40.3 & 0.010 & 3.91 & 31.2 & 0.005 \\
\hline 50 & 3.34 & 45.7 & 0.007 & 3.58 & 38.7 & 0.010 & 3.92 & 31.0 & 0.003 \\
\hline 55 & 3.38 & 44.4 & 0.007 & 3.63 & 37.4 & 0.010 & 3.94 & 30.6 & 0.002 \\
\hline 60 & 3.41 & 43.5 & 0.006 & 3.69 & 36.0 & 0.010 & 3.95 & 30.4 & 0.002 \\
\hline
\end{tabular}

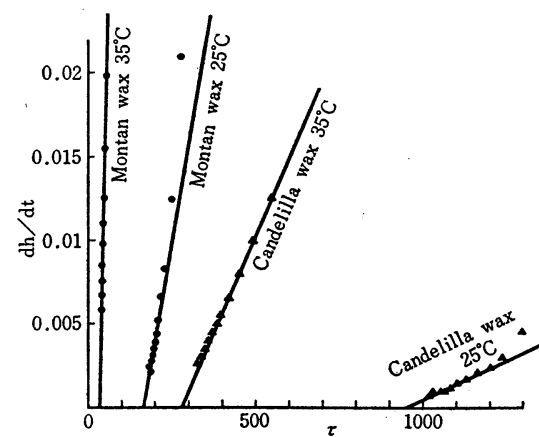

Fig.-6 Correlation of $\mathrm{dh} / \mathrm{dt}$ with $\tau$ at $25^{\circ}$ and $35^{\circ} \mathrm{C}$

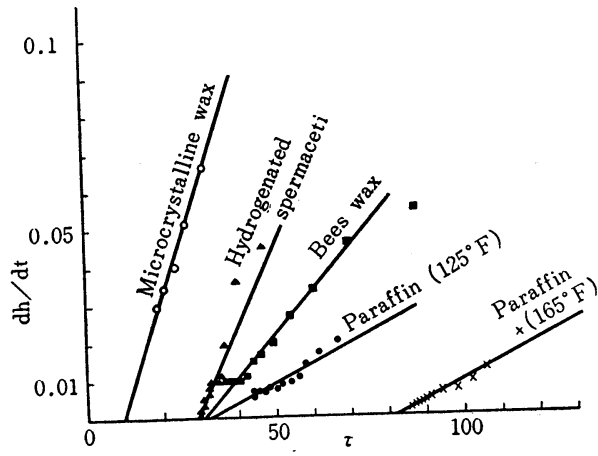

Fig.-7 Correlation of $\mathrm{dh} / \mathrm{dt}$ with $\tau$ at $25^{\circ} \mathrm{C}$ 
Table-5 Results of Experiments

\begin{tabular}{|c|c|c|c|c|c|c|c|c|c|}
\hline Waxes & \multicolumn{3}{|c|}{ Microcystalline wax } & \multicolumn{3}{|c|}{ Candelilla wax } & \multicolumn{3}{|c|}{ Montan wax } \\
\hline Temp & \multicolumn{3}{|c|}{$25^{\circ} \mathrm{C}$} & \multicolumn{3}{|c|}{$35^{\circ} \mathrm{C}$} & \multicolumn{3}{|c|}{$35^{\circ} \mathrm{C}$} \\
\hline $\begin{array}{l}\text { Time } \\
(\mathrm{sec})\end{array}$ & $\begin{array}{c}\bar{h} \\
(\mathrm{~mm})\end{array}$ & $\begin{array}{c}\tau \\
\left(\mathrm{g} / \mathrm{mm}^{2}\right)\end{array}$ & $\begin{array}{c}d h / d t \\
(\mathrm{~mm} / \mathrm{sec})\end{array}$ & $\begin{array}{c}\bar{h} \\
(\mathrm{~mm})\end{array}$ & $\begin{array}{c}\tau \\
\left(\mathrm{g} / \mathrm{mm}^{2}\right)\end{array}$ & $\begin{array}{c}d h / d t \\
(\mathrm{~mm} / \mathrm{sec})\end{array}$ & $\begin{array}{c}\bar{h} \\
(\mathrm{~mm})\end{array}$ & $\begin{array}{c}\tau \\
\left(\mathrm{g} / \mathrm{mm}^{2}\right)\end{array}$ & $\begin{array}{c}d h / d t \\
(\mathrm{~mm} / \mathrm{sec})\end{array}$ \\
\hline 5 & 3.48 & 41.4 & 0.112 & 0.998 & 642 & 0.022 & 2.704 & 74.5 & 0.068 \\
\hline 10 & 3.87 & 32.0 & 0.066 & 1.076 & 550 & 0.0125 & 2.920 & 62.5 & 0.032 \\
\hline 15 & 4.16 & 26.8 & 0.051 & 1.132 & 495 & 0.0100 & 3.050 & 56.5 & 0.024 \\
\hline 20 & 4.39 & 23.4 & 0.040 & 1.180 & 452 & 0.0080 & 3.155 & 52.0 & 0.019 \\
\hline 25 & 4.56 & 21.2 & 0.034 & 1.216 & 425 & 0.0065 & 3.240 & 49.0 & 0.0155 \\
\hline 30 & 4.72 & 19.4 & 0.029 & 1.243 & 405 & 0.0055 & 3.309 & 46.5 & 0.0125 \\
\hline 35 & & & & 1.271 & 387 & 0.0050 & 3.364 & 44.5 & 0.0110 \\
\hline 40 & & & & 1.291 & 374 & 0.0045 & 3.415 & 43.2 & 0.0098 \\
\hline 45 & & & & 1.312 & 362 & 0.0040 & 3.462 & 41.3 & 0.0085 \\
\hline 50 & & & & 1.332 & 350 & 0.0035 & 3.500 & 40.8 & 0.0075 \\
\hline 55 & & & & 1.347 & 342 & 0.0030 & 3.536 & 40.0 & 0.0066 \\
\hline 60 & & & & 1.364 & 333 & 0.0027 & 3.566 & 39.0 & 0.0058 \\
\hline
\end{tabular}

Table-6 Needle penetration number and yield value of waxes

\begin{tabular}{l|r|r|r}
\hline \multicolumn{1}{c|}{ Waxes } & NP. & $\left(25^{\left.{ }^{\circ} \mathrm{C}\right)}\right.$ & $\left(35^{\circ} \mathrm{C}\right)$ \\
\hline Candelilla wax & 3 & 950 & 280 \\
Montan wax & 8 & 164 & 34 \\
Paraffin $\left(165^{\circ} \mathrm{F}\right)$ & 12 & 82 & - \\
Paraffin $\left(125^{\circ} \mathrm{F}\right)$ & 21 & 32.5 & - \\
Bees wax & 22 & 31 & - \\
Hydrogenated spermaceti & 26 & 29 & - \\
Microcrystalline wax & 31 & 10 & - \\
\hline
\end{tabular}

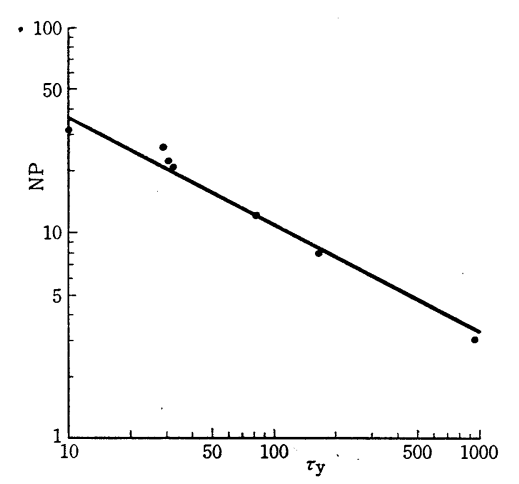

Fig.-8 Correlation of needle penetration number with yield value at $25^{\circ} \mathrm{C}$

入度数 $(N P)$ の関係は, Fig.-8 のようになった。

$\log \tau_{\boldsymbol{y}}$ と $\log N P$ は直線的関係になり，実験式とし て(9)式を得ることができる。

$$
\begin{aligned}
\log N P & =2.2-0.6 \log \tau_{y} \\
\text { 又は } \frac{1}{N P} & =\frac{\tau_{y}^{0.6}}{10^{2.2}}
\end{aligned}
$$

(9)式はこれ等のワックスにおいて針入度数の逆数は 降伏応力の 0.6 乗に比例することを示しており, このこ とは, 従来経験的な数值としてワックスの「硬さ」の参 考に使われてきた針入度が，少なくとも本報に示されて いるワックスあるいはこれ等に類似した「硬さ」のワッ クスにおいては，定量的な「硬さ」の基準と考えてよい ことを示していると思われる。

最後に本研究の発表を許可された日興理化学産業株式 会社社長石井久雄氏に深謝いたします。

\section{文献}

1) A.H. Warth, "Chemistry and Technology of waxes, Reinhold"'(1960), New York.

2) D.G.F., "Gemeinschaft sarbeiten der D.G.F. 30 mitteilung Neubearbeitung der Einheiteichen Unter suchungs-methoden für die Fett-und wachsindustrie"

3) ASTM, D 1321-65

4) JIS, K-2530

5) A. H. Warth, p. 611

6) ibid., p. 612

7) ibid., p. 618

8) D.G.F., Fett, Seifer. Anstrichmitteln, 58, 11(1956)

9) ibid. 68, 25 (1966)

10) D. Tabor, "The hardness of metals" chapter 7 (1951) oxford.

11) W. W. Pendelton, J. Applied phys, 14 170-180 (1943)

12) E. O. Rhodes and E. W. Volkmann, J. Applied Phys, 8492 (1937) 